SUS-RURI: Proceedings of a Workshop on Developing a Convergence Sustainable Urban Systems Agenda for Redesigning the Urban-Rural Interface along the Mississippi River Watershed held in Ames, lowa, August 12-13, 2019

\title{
Directions for \\ Environmentally \\ Sustainable Residential \\ Development Research in \\ the Urban-Rural Interface
}

\section{Asli Gocmen}

Published on: Jan 14, 2020

DOI: 10.31274/3d9ea6a4.7a5bbb7b

License: Creative Commons Attribution 4.0 International License(CC-BY 4.0). 
As planners and environmental professionals, we are facing challenging times. Over half of the world's population now lives in urban areas, with an expected increase of 2.5 billion people in the next 35 years. This increase in population will require significant expansion of urban and urbanized land area coverage, resulting in mostly irreversible damage to ecosystems (Seto et al., 2011). Between 1945 and 2007, urbanized land area in the United States alone increased by 73,000 square miles, roughly the size of the State of Washington (Nickerson et al., 2011) and manifested itself in low-density, land use-segregated, and automobile-dependent development patterns, with many unintended negative consequences. Recently, planners and other sustainability advocates have been striving to reshape our landscapes into more sustainable patterns. In this piece, I will concentrate on important research directions concerning conservation subdivision design (CSD), a residential development technique promoted as a more sustainable alternative to conventional suburban and exurban development in the urban-rural interface. Especially since the 1990s, CSD has been popular; over 300,000 acres of land-a figure corresponding to almost half of the entire state of Rhode Island-is estimated to have been developed as a conservation subdivision nationwide (Milder and Clark, 2011).

Conservation subdivision design is promoted on a number of economic, social and environmental benefits, and is claimed to be a win-win-win scenario for residents, developers, and communities in general (Arendt, 1996; Carter, 2009; City of Olympia, 1995; NEMO, 1999; Pejchar et al., 2007; Tutle et al., 2007). However, empirical research is limited in geographic scope and in number, and therefore, we do not have strong evidence on its effectiveness as a sustainable way to develop the urban-rural interface. In this piece, I will discuss the promoted benefits and point to areas where we are lacking evidence either because there is limited empirical work or because empirical work has conflicting or inconclusive findings.

Conservation subdivision design clusters residences on smaller lots than in conventional subdivisions, often on lots smaller than what the local zoning ordinances require. In return, the remainder of the subdivision's land is set aside as common open space. Milder and Clark (2011) estimated that nationwide, at least about 100,000 acres have been set aside as open space in conservation subdivisions. In order to achieve the most ecosystem services, these common open spaces should be based on the ecological value of the land. In providing design guidelines, Arendt, who has been the primary proponent of the design technique has suggested that at least half of the subdivision's buildable lands (i.e., areas that can safely support residential 
development) should be reserved for common open space (Arendt, 1996). However, in practice, these guidelines have not always been met (Göçmen, 2014b; Milder and Clark, 2011). For instance, in Waukesha County, Wisconsin, where 54 conservation subdivisions were built between 1990 and 2005, the percentage of open spaces ranged from $16 \%$ to $80 \%$ of total subdivision land (Göçmen, 2014b). Given that there is great variation in implementation of the design, it is imperative that we investigate evidence to the benefits claims.

\section{Posited Economic Benefits of CSD, Supporting Empirical Evidence, and Future Research Directions}

Conservation subdivision design promises higher property appreciation values, marketing and sales advantages, and reduced development costs. Most of these potential benefits are attributable to having common open spaces. For instance, nearby open spaces and view of nature from home are expected to help increase property demand, premiums, and appreciation values, and contribute to faster sales (see Figure 1). Proponents also claim that as an outcome of the clustering of residences, development costs in conservation subdivisions will be lower due to shortened road and utility networks. 


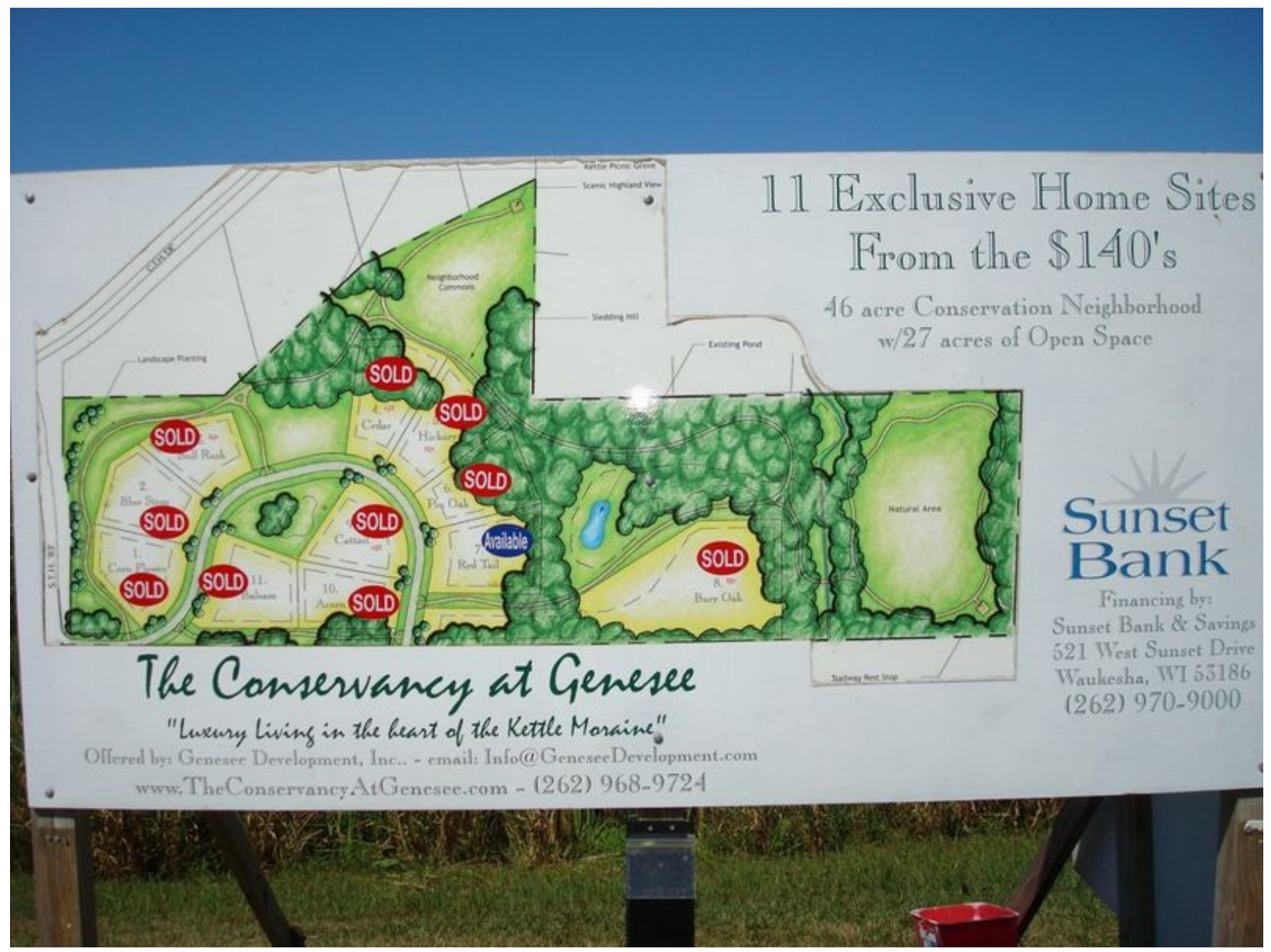

Figure 1: Marketing Advantage in a Conservation Subdivision in Town of Genesee, Wisconsin: "Luxury Living in the Heart of the (State Forest) Kettle Moraine." Photo taken by the author.

There is vast amount of literature on the relationship between open spaces and property values in general (see for instance, Hardie et al., 2007; Irwin, 2002; McConnell and Walls, 2005; Thorsnes, 2002). In general, studies based on hedonic models find that open space, especially which restricts development or is adjacent to property, has a significant positive contribution to property values.

Yet, the literature is sparse on how open space contributes to property values in conservation subdivisions specifically and the trade-offs between lot sizes and availability of open spaces. In a study based on nearly 3,400 house sales in 89 subdivisions in the Baltimore-Washington D.C. area, Kopits and colleagues (2007) found that both lot sizes and the amount of subdivision open spaces played an important role in house prices. At the same time, the study showed that larger lot sizes added more value to house prices in these subdivisions than open space. The authors found that a $10 \%$ increase in private lot size increased house prices by $0.6 \%$, whereas 
a $10 \%$ increase in subdivision open space was only associated with a $0.1 \%$ increase. Other studies corroborate the importance of lot sizes such that lot size is found to contribute more to property value than open space (Bowman et al; 2009; Peiser and Schwann, 1993). In a comparative study of 87 conservation and 84 conventional subdivisions in Town of South Kingstown, Rhode Island, Mohamed (2006) found that conservation subdivisions had a price premium and that conservation subdivision lots sold for 10-14\% higher prices compared to conventional subdivision lots. A Colorado study by Hannum et al. (2012) similarly found price premiums for conservation subdivision lots. In a study in Cedar Rapids, Iowa, Bowman and colleagues (2009) found that while conservation subdivision properties had a higher appreciation rate than conventional subdivision properties, sale times of lots did not differ among different types of subdivisions. This latter finding is at odds with that of Mohamed's Rhode Island study, in which he found conservation subdivision lots sold almost twice as fast as conventional subdivision lots did.

While there has been important empirical work on property values, and marketing and sales advantages, there is very limited empirical work on the cost-savings benefits of CSD. For instance, there is no evidence of shortened road networks in conservation subdivisions that could translate into cost-savings. The only study that examined road networks found that conservation and conventional subdivisions created similar amounts of impervious surfaces per property in general and that the road surface area was not statistically different among alternative subdivision types (Göçmen, 2014b). Furthermore, there is no clear evidence that there are other costs-savings from developing a conservation subdivision. During the development permitting process, often, developers of conservation subdivisions are subject to additional fees and additional steps (requiring significantly extended review periods, which translate into loss of profits) and that building around natural features as opposed to bulldozing them can be a major hurdle and expense (Göçmen, 2014a). Because evidence is limited and contrary to expectations in some cases, a needed future research direction involves an evaluation of the posited economic benefits, especially in the area of costsavings.

\section{Posited Social and Psychological Benefits of CSD, Supporting Empirical Evidence, and Future Research Directions}

CSD is posited to provide an opportunity to be near nature on a regular basis and to bring increased quality of life and neighborhood satisfaction to individuals. Time in nature, a view of nature from home, and residential proximity to natural areas have 
been linked to psychological benefits and neighborhood satisfaction (Kaplan, 2001; Kearney, 2006). Still, it is important to investigate if conservation subdivisions do bring these benefits since open spaces can take many different forms in conservation subdivisions and do not necessarily involve natural features.

In a Michigan-based study, Austin found general satisfaction with living in conservation subdivisions among residents (e.g., seeing grasshoppers and frogs in the yard, having more neighborly interactions because of common open spaces and trails); however, she also discovered some dissatisfaction among residents. Common open spaces raised concerns and dissatisfaction, for instance, due to maintenance issues and due to their proximity to homes, jeopardizing privacy (Austin, 2004). While Kaplan and colleagues did not study satisfaction with neighborhood in their comparative residential study involving conservation and conventional subdivisions, they found that satisfaction with nearby natural areas was significantly higher among conservation subdivision residents (Kaplan et al., 2004). Comparative empirical work is generally lacking in the social and psychological domain and needs to be a future research direction. It is important to know whether conservation subdivision residents, when compared to residents of conventional suburban and exurban subdivisions, have higher satisfaction with their quality of life and with their neighborhoods.

\section{Posited Environmental Benefits of CSD, Supporting Empirical Evidence, and Future Research Directions}

CSD has the potential to bring many environmental benefits, mostly for wildlife and water quality. Proponents of CSD claim that it preserves ecologically significant and environmentally sensitive lands within a subdivision, helps to create a regional network of such lands, and contributes to better water quality through reduced impervious surfaces that limit surface runoff and the integration of best management practices. The setting aside of ecologically significant and environmentally sensitive lands within a subdivision as open space can help maintain wildlife habitat and biodiversity, control erosion, reduce soil compaction, and help protect wetlands, streams, and lakes.

Empirical work examining land protection found significant amount of land set aside in common open space: 2,500 acres in a southeastern Wisconsin county (Göçmen, 2014b); 11,200 acres in the Midwest and Northeast (Bosworth, 2007), and 850 acres of farmland in a New York town (Brabec, 2001). Studies have found other environmental benefits in the areas of carbon storage and sequestration (Vaughn et al., 2014), wildlife (Farr et al., 2017), and water quality (Nassauer et al., 2004). 
Similar to economic and social domains, the evidence of how well conservation subdivisions do environmentally when compared to conventional subdivisions is limited. Multiple studies show that wildlife habitats are destroyed to a lower extent with clustering residences (Göçmen, 2014b; Gonzalez- Abraham et al., 2007). In cluster developments, such as in conservation subdivisions, the zone of influence by each house is expected to overlap with other houses to a greater extent than in conventional subdivisions where houses are placed on larger lots, and therefore, conservation subdivisions are expected to reduce the negative impacts on wildlife (Odell et al., 2003). While a recent Colorado-based study found conservation subdivisions performed as well as undeveloped lands in habitat provision for birds and some mammals (Farr et al., 2017), Lenth et al. (2006), in another Colorado-based study, found that undeveloped land provided significantly higher opportunities for wildlife presence than conservation developments. Furthermore, the study by Lenth and colleagues did not find any differences in wildlife attributes (e.g., presence of mammals, density of songbirds) among conservation versus conventional developments. The authors suggested composition and configuration of open spaces as likely factors for the lack of differences. The study Farr and colleagues also points to the importance of composition of open spaces and argues that proportion and size of common open space, and natural land cover all contributed to wildlife benefits for birds and mammals in conservation subdivisions (Farr et al., 2017). An important research direction is continued investigations into differences between conservation and conventional subdivisions with studies based on wildlife observations.

The water quality benefits of conservation subdivisions have also been studied, but these studies are limited to a large extent to modeled efforts and are based on hypothetical developments. An exception is Nassauer et al.'s (2004) study, which investigated water quality in different types of developments in two southeast Michigan watersheds. The study found conservation subdivisions to provide multiple water quality benefits, including lower nonpoint source pollution and higher number of species, when compared to conventional exurban subdivisions.

In the modeled studies based on hypothetical developments, stormwater runoff is modeled to be more similar to pre-development conditions in conservation subdivisions than in conventional subdivisions (see for instance, Brander et al., 2004; Bosch et al., 2003; Williams and Wise, 2006). The smaller amounts of runoff in these hypothetical conservation subdivisions are attributed to the presence of stormwater retention ponds (Williams and Wise, 2006) and land being kept in its natural state (Brander et al., 2004). However, as mentioned before, implementation of CSD takes many different 
forms: some subdivisions do not contain stormwater retention or detention ponds and in some others, common open spaces primarily consist of mown lawn. Therefore, in water quality-related research, investigation of stormwater runoff in conservation subdivisions that are already developed would be very beneficial.

I have identified some gaps and future directions concerning CSD research. I believe additional empirical research is needed to substantiate or refute the claims made about CSD and that we need to move beyond modeled studies and investigate the actual implementation of the technique, for instance, in the case of water quality. Such research can help discover where the implementation of the technique falls short of its goals and identify ways that professionals can change the way they design, approve, and develop conservation subdivisions to increase ecological benefits.

\section{Other Potential Research Directions for CSD}

Another critical future research direction involves investigating how particular characteristics of conservation subdivisions and in particular their open spaces are related to ecological indicators (e.g., water quality, wildlife presence and movement); social dimensions (e.g., satisfaction with neighborhood), and economic advantages (e.g., sales premiums). In this regard, investigations could integrate landscape ecology principles to examine the composition (e.g., total size, land cover type) and configuration (e.g., shape and mean size of patches, placement) of open spaces and their influences on the posited benefits. Farr and colleagues (2017) have integrated landscape metrics in investigating wildlife presence in conservation subdivisions and have provided useful insights for CSD implementation with their findings. Potential research questions include whether residents of conservation subdivisions with one large intact common open space are more satisfied than residents of conservation subdivisions with many small common open spaces distributed fairly evenly across the subdivision.

Another needed future research direction involves collaborations from social, biological, and physical scientists to examine relationships in human, natural, and engineered systems. Empirical work in this area could involve examining if environmental knowledge affects support for environmentally sustainable residential development including CSD. For example, are planners, developers, and residents with more knowledge of ecology and the environment more likely to live in, approve, and develop subdivisions of higher environmental quality when compared to individuals who are less knowledgeable? Prior empirical work in this area is very limited and inconclusive (Göçmen, 2014a; Hostetler and Noiseux, 2010). 
Finally, I suggest we broaden the geographical scope of conservation subdivision investigations and include communities with different regulatory, physical, and sociodemographic characteristics. While conservation subdivisions are implemented throughout the United States, most empirical work is concentrated in a few states including Colorado (e.g.; Farr et al., 2017; Feinberg et al., 2015; Hannum et al., 2012), Florida (e.g., Hostetler and Noiseux 2010; Vaughn et al., 2014); Michigan (e.g., Austin, 2004; Göçmen, 2009; Kaplan et al., 2004), Iowa (e.g., Thompson et al., 2009; 2012) and Wisconsin (Göçmen, 2013; 2014a; 2014 b). Based on Milder and Clark's (2011) estimate of 34,000 acres dedicated to conservation subdivisions in the watershed, the Upper Mississippi Watershed would provide a good laboratory for future work.

\section{References}

Arendt, R. G. 1996. Conservation design for subdivisions: A practical guide for creating open space networks. Washington, DC: Island Press.

Austin, M. 2004. Resident perspectives of the open space conservation subdivisions in Hamburg Township, Michigan. Landscape and Urban Planning. 69(2-3): 245-253. https://doi.org/10.1016/j.landurbplan.2003.09.007.

Bosch, D. J., Lohani, V. K., Dymond, R. L., Kibler, D. F., and Stephenson, K. 2003. Hydrological and fiscal impacts of residential development: Virginia case study. Journal of Water Resources Planning and Management. 129(2): 107-114.

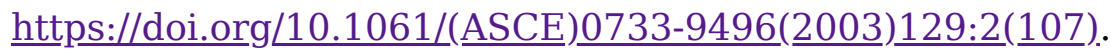

Bosworth, K. 2007. Conservation subdivision design: Perceptions and reality. Unpublished master's thesis. University of Michigan, Ann Arbor, MI. http://hdl.handle.net/2027.42/50466.

Bowman, T., Thompson, J., and Colletti, J. 2009. Valuation of open space and conservation features in conservation subdivisions. Journal of Environmental Management. 90(1): 321-330. https://doi.org/10.1016/j.jenvman.2007.10.008.

Bowman, T., Thompson, J., and Tyndall, J. 2012. Resident, developer, and city staff perceptions of LID and CSD subdivision design approaches. Landscape and Urban Planning. 107(1): 43-54. https://doi.org/10.1016/j.landurbplan.2012.04.011.

Brabec, E. 2001. An evaluation of the effectiveness of cluster development in the Town of Southampton, New York. Urban Ecosystems 4: 27-47. https://doi.org/10.1023/A:1021825601746. 
Brander, K., E., Owen, K. E., and Potter, K. W. 2004. Modeled impacts of development type on runoff volume and infiltration performance. Journal of the American Water Resources Association 40(4): 961-969. https://doi.org/10.1111/j.17521688.2004.tb01059.x.

Carter, T. 2009. Developing conservation subdivisions: Ecological constraints, regulatory barriers, and market incentives. Landscape and Urban Planning 92: 117124. https://doi.org/10.1016/j.landurbplan.2009.03.004.

City of Olympia. 1995. Impervious surface reduction study. Final Report. Retrieved on September 22, 2008 from

http://www.ci.olympia.wa.us/ /media/Files/PublicWorks/PDFs/WaterResources/Impervi ous-Surface-Reduction-Study-1995-072407.ashx.

Farr, C. M., Pejchar, L., and Reed, S. E. 2017. Subdivision design and stewardship affect bird and mammal use of conservation developments. Ecological Applications 27(4): 1236-1252. https://doi.org/10.1002/eap.1517/

Feinberg, D. S., Hostetler, M. E., Reed, S. E., Pienaar, E. F., and Pejchar, L. 2015. Evaluating management strategies to enhance biodiversity in conservation developments: Perspectives from developers in Colorado, USA. Landscape and Urban Planning 136: 87-96. https://doi.org/10.1016/j.landurbplan.2014.12.002.

Gonzalez-Abraham, C., Radeloff, V., Hawbaker, T., Hammer, R., Stewart, S., and Clayton, M. 2007. Patterns of houses and habitat loss from 1937 to 1999 in Northeast Wisconsin, USA. Ecological Applications 117: 2011-2023. https://doi.org/10.1890/061963.1.

Göçmen, Z. A. 2014a. Exploring land developer perspectives on conservation subdivision design and environmentally sustainable land development. Environmental Management 54(5): 1208-1222. https://doi.org/10.1007/s00267-014-0354-3.

Göçmen, Z. A. 2014b. Assessing the environmental merits of conservation subdivision design. Journal of Planning Education and Research 34(2): 203-220. https://doi.org/10.1177/0739456X13512526.

Göçmen, Z. A. 2013. Barriers to successful implementation of conservation subdivision design: A closer look at land use regulations and subdivision permitting process. Landscape and Urban Planning. 110: 123-133. https://doi.org/10.1016/j.landurbplan.2012.11.002. 
Göçmen, Z. A. 2009. Relationships between residential development and the environment: Examining resident perspectives. Journal of Planning Education and Research. 29(1): 54-66. https://doi.org/10.1177/0739456X09339065.

Hannum, C., Laposa, S., Reed, S., Pejchar, L, and Ex, L. 2012. Comparative analysis of housing in conservation developments: Colorado case studies. Journal of Sustainable Real Estate. 4(1): 149-176.

Hardie, I., Lichtenberg, E., and Nickerson, S. J. 2007. Regulation, open space, and the value of land undergoing residential subdivision. Land Economics. 83(4): 458-474. https://doi.org/10.3368/le.83.4.458.

Hostetler, M. and Noiseux, K. 2010. Are green residential developments attracting environmentally savvy homeowners? Landscape and Urban Planning. 94: 234-243. https://doi.org/10.1016/j.landurbplan.2009.10.008.

Irwin, E. G. 2002. The effects of open space on residential values. Land Economics. 78(4): 465-480. https://doi.org/10.2307/3146847.

Kaplan, R. 2001. The nature of the view from home: Psychological benefits. Environment and Behavior. 33(4): 507-542.

https://doi.org/10.1177/00139160121973115.

Kaplan, R., Austin, M. E., and Kaplan, S. 2004. Open space communities: Resident perceptions, nature benefits, and problems with terminology. Journal of the American Planning Association. 70(3): 300-312. https://doi.org/10.1080/01944360408976380.

Kearney, A. R. 2006. Residential development patterns and neighborhood satisfaction: Impacts of density and nearby nature. Environment and Behavior. 38(1): 112-139. https://doi.org/10.1177/0013916505277607.

Kopits, E., McConnell, V., and Walls, M. 2007. The Trade-off between Private Lots and Public Open Space in Subdivisions at the Urban-rural Fringe. American Journal of Agricultural Economics. 89(5): 1191-1197. https://doi.org/10.1111/j.14678276.2007.01083.x.

Lenth, B. A., Knight, R. L., and Gilbert, W. C. 2006. Conservation value of clustered housing developments. Conservation Biology 5: 1445-1456.

https://doi.org/10.1111/j.1523-1739.2006.00491.x. 
McConnell, V. and Walls, M. 2005. The Value of Open Space: Evidence form Studies of Non-market Benefits. Accessed on 31 March 2012 at:

https://media.rff.org/documents/RFF-REPORT-Open20Spaces.pdf.

Milder, J. C. and S. Clark. 2011. Conservation development practices, extent, and land use effects in the United States. Conservation Biology 25(4): 697-707. https://doi.org/10.1111/j.1523-1739.2011.01688.x.

Mohamed, R. 2006. The economics of conservation subdivisions: Price premiums, improvement costs, and absorption rates”. Urban Affairs Review 41(3): 376-99. https://doi.org/10.1177/1078087405282183.

Nassauer, J. I., Allan, J. D., Johengen, T., Kosek, S. E., and Infante, D. 2004. Exurban residential subdivision development: Effects on water quality and public perception. Urban Ecosystems 7(3): 267-281.

https://doi.org/10.1023/B:UECO.0000044039.65448.48.

NEMO (Nonpoint Education for Municipal Officials). 1999. Conservation subdivisions: A better way to protect water quality, retain wildlife, and preserve rural character. NEMO Project Fact Sheet 9. A Joint Publication of Conn Cooperative Extension's NEMO project and the Natural Lands Trust.

Nickerson, C., Ebel, R., Borchers, A., and Carriazo, F. (2011). Major Uses of Land in the United States, 2007. USDA. Accessed in May 2013 at:

http://hdl.handle.net/20.500.11822/17914.

Odell, E. A., Theobald, D., and Knight, R. L. 2003. Incorporating ecology into land use planning: The songbirds' case for clustered development. Journal of the American Planning Association. 69(1): 72-82. https://doi.org/10.1080/01944360308976294.

Peiser R. B. and Schwann, G. M. 1993. The private value of public open space within subdivisions. Journal of Architectural and Planning Research. 10(2): 91-104.

Pejchar, L., Morgan, P. M., Caldwell, M. R., Palmer, C., and Daily, G. C. 2007. Evaluating the potential for conservation development: Biophysical, economic, and institutional perspectives. Conservation Biology 21(1): 69-78.

https://doi.org/10.1111/j.1523-1739.2006.00572.x.

Seto, K. C.., Fragkisa, M., Guneralp, B., and Reilly, M. K. 2011. A meta-analysis of global urban land expansion. PLoS ONE 6: e23777.

https://doi.org/10.1371/journal.pone.0023777 
Thorsnes, P. 2002. The value of a suburban forest preserve: Estimates from sales of vacant residential building lots. Land Economics. 78(3): 426-443.

https://doi.org/10.2307/3146900.

Tutle, C. Q., Enz, J. C., and Apfelbaum, S. I. 2007. Cost savings in ecologically designed conservation developments. Accessed on April 22, 2013 at:

https://www.researchgate.net/profile/Steven_Apfelbaum/publication/268006250 Cost S avings in Ecologically_Designed_Conservation_Developments/links/54678cbe0cf2397f7 $\underline{\text { 82be9dd/Cost-Savings-in-Ecologically-Designed-Conservation-Developments.pdf }}$

Vaughn, R. M., Hostetler, M. Escobedo, F. J., and Jones, P. 2014. The influence of subdivision design and conservation of open space on carbon storage and sequestration. Landscape and Urban Planning. 131: 64-73.

https://doi.org/10.1016/j.landurbplan.2014.08.001.

Williams, E., and Wise, W. 2006. Hydrologic impacts of alternative approaches to storm water management and land development. Journal of the American Water Resources Association 42: 443-455. https://doi.org/10.1111/j.1752-1688.2006.tb03849.x.

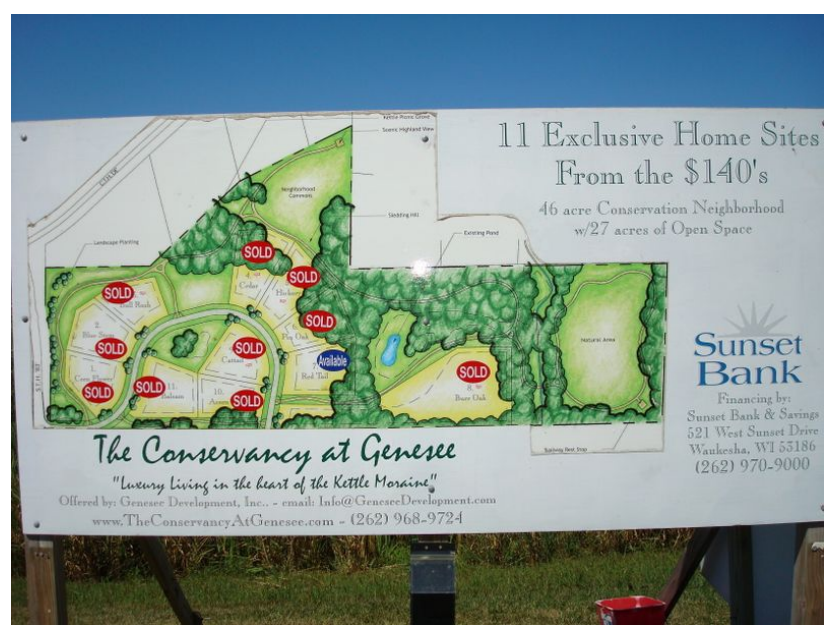

\section{Asligül Göçmen}

University of Wisconsin-Madison, Department of Geography \& Nelson Institute for Environmental Studies gocmen@wisc.edu

This event is supported by the National Science Foundation, Award \#1929601. Any opinions, findings, and conclusions or recommendations expressed in this material are those of the author(s) and do not necessarily reflect the views of the National Science Foundation. 
SUS-RURI: Proceedings of a Workshop on Developing a Convergence Sustainable Urban Systems Agenda for Redesigning the Urban-Rural Interface along the Mississippi River Watershed held in Ames, lowa, August 12-13, 2019
Directions for Environmentally Sustainable Residential Development Research in the Urban-Rural Interface 